\title{
PRODUÇÃO E CARACTERIZAÇÃO DE AMILASE DE Fusarium moniliforme E Aspergillus flavus
}

\author{
EDSON LUIZ ZANGRANDO FIGUEIRA ** \\ MARCELA COLOGNESI DE SÁ *** \\ ELZA IOUKO IDA * \\ ELISA YOKO HIROOKA *
}

\begin{abstract}
Considerando o interesse econômico da cultura do milho, alvo de ataque de fungos micotoxigênicos, esta investigação teve por objetivo a produção e caracterização bioquímica parcial de amilase das principais espécies problemáticas (Fusarium moniliforme e Aspergillus flavus). Empregando-se cultivo em caldo de milho verde, adicionado de milho triturado, a maximização da produção de amilase de $F$. moniliforme e A. flavus ocorreu no $15^{\circ}$ dia de fermentação. Submetendo-se o sobrenadante de cultura à precipitação fracionada com sulfato de amônio, entre 60 a $90 \%$ de saturação, obteve-se a amilase fúngica, que foi caracterizada perante $\mathrm{pH}$, temperatura e estabilidade térmica por metodologia de superfície de resposta. Em ambos os grupos fúngicos, a atividade enzimática foi maximizada em temperatura próxima a $40{ }^{\circ} \mathrm{C}$, com pH em torno de 6,7 para amilase de $F$. moniliforme e 5,5 para $A$. flavus. A máxima estabilidade térmica da enzima de F. moniliforme ocorreu próximo a $21,0^{\circ} \mathrm{C}$.
\end{abstract}

\section{INTRODUÇÃO}

O milho é uma cultura mundial, aparentemente originária do México, que se difundiu da América para outros continentes (WATSON \& RAMSTAD, 1987). Destaca-se entre as principais culturas pela produção anual de 440

* Docentes do Programa de Pós-Graduação em Ciência de Alimentos, Departamento de Tecnologia de Alimentos e Medicamentos, Centro de Ciência de Alimentos (CCA), Universidade Estadual de Londrina (UEL), Londrina - PR.

(e-mail: hirooka@npd.uel.br).

** Doutorando e Bolsista do CNPq em Ciência de Alimentos, UEL.

*** Estagiária do Programa Institucional de Bolsas de Iniciação Científica (PIBIC), CNPq, UEL. 
milhões de toneladas, das quais os Estados Unidos produzem aproximadamente $50 \%$ do total, enquanto que o Brasil participa com $8 \%$ (CÔRTES, 1997).

A composição de milho favorece 0 ataque de insetos predadores e a deterioração fúngica, com destaque para $F$. moniliforme, $F$. proliferatum, $F$. oxysporum, Aspergillus spp, A. flavus, A. parasiticus, Diploidia spp e Penicillium spp (GONZÁLEZ et al., 1995).

Os danos fúngicos no milho manifestam-se sob forma de perda de peso, descoloração, necrose dos grãos e conseqüente produção de micotoxinas, cuja presença afeta a liberação e comercialização internacional de produtos agrícolas (JULIAN et al., 1995).

F. moniliforme e $F$. proliferatum, as espécies mais freqüentes, caracterizam-se pela produção de fumonisinas (LOGRIECO et al., 1995, GONZÁLEZ et al., 1995, THIEL et al., 1991; JULIAN et al., 1995). Este grupo de micotoxinas, descoberto por BEZUIDENHOUT et al. (1988) causa leucoencefalomalácia em equinos (BEZUIDENHOUT et al., 1988), síndrome de edema pulmonar em suínos (ROSS et al., 1991), depressão no desenvolvimento de aves (WEIBKING et al., 1993) e câncer esofágico humano (NORRED \& VOSS, 1994; BULLERMAN \& DRAUGHON, 1994).

No milho brasileiro, a pesquisa de $F$. moniliforme e fumonisinas revelou incidência do fungo em $85 \%$ das 48 amostras estudadas com ocorrência de 100 e 97,4\%, respectivamente, para fumonisinas $\mathrm{FB}_{1}$ e $\mathrm{FB}_{2}$ (HIROOKA et al., 1996). Situação similar foi relatada na Comunidade Européia, na África e em Honduras (DOKO et al., 1995; LOGRIECO et al., 1995; GONZÁLEZ et al., 1995; JULIAN et al., 1995). Esta constatação indica que o controle fitossanitário é fundamental para assegurar a qualidade dos produtos consumidos. Não obstante, além de elevado custo, os pesticidas sintéticos empregados na atualidade ocasionam problemas ambientais, sociais e agropecuários (KRIEGER \& SCHUTTERER apud GOMES \& XAVIER-FILHO, 1994). Para contornar tais problemas, pesquisas sobre mecanismos naturais de defesa das plantas contra patógenos despontaram como solução adequada para aumentar a produtividade agrícola, com a vantagem de minimizar a aplicação de pesticidas (GOMES \& XAVIER-FILHO, 1994). Entre estes mecanismos, o inibidor de amilase vem sendo apontado como ferramenta promissora no controle de fitopatógenos (GATEHOUSE, 1992). Sendo o amido, o componente que participa com maior percentagem nos grãos, constitui-se alvo de ataque das amilases fúngicas, que propiciam melhor crescimento micelial e subseqüente deterioração/produção de toxinas.

O presente trabalho propôs a padronização da produção de amilase de $F$. moniliforme e $A$. flavus em substrato à base de milho, seguida de 
caracterização de enzimas obtidas perante $\mathrm{pH}$, temperatura e estabilidade térmica, empregando-se metodologia de superfície de resposta.

\section{MATERIAL E MÉTODOS}

\subsection{MICRORGANISMOS}

Fungos relacionados com micotoxicologia de milho, isolados pelo Departamento de Tecnologia de Alimentos e Medicamentos/CCA/UEL, foram empregados para a produção de amilase.

F. moniliforme $113 \mathrm{~F}$, isolado de ração de milho envolvido em intoxicação animal, caracterizou-se pela produção inicial de 54,21 e $87,31 \mu \mathrm{g} / \mathrm{g}$, respectivamente, de $\mathrm{FB}_{1}$ e $\mathrm{FB}_{2}$. A. flavus produtora de aflatoxina foi isolada de ração contaminada e analisada pelo controle de qualidade.

As linhagens foram mantidas a $4{ }^{\circ} \mathrm{C}$ com repique semestral em ágar batata dextrose (BDA).

\subsection{MEIO MILHO}

A amilase de $F$. moniliforme ou de $A$. flavus foi produzida em meio constituído por sobrenadante de milho verde, adicionado de $2 \%$ de milho maduro triturado, esterilizado a $121^{\circ} \mathrm{C}$ por 15 min. $\mathrm{O}$ sobrenadante de milho verde foi obtido pela homogeneização de $350 \mathrm{~g}$ de milho verde com $250 \mathrm{~mL}$ de água destilada, seguida de centrifugação a $900 \times \mathrm{g}$ por 10 minutos (FIGUEIRA, 1999).

\subsection{PADRONIZAÇÃO DE FERMENTAÇÃO PARA AMILASES FÚNGICAS}

Os conídeos fúngicos, previamente ativados a $25^{\circ} \mathrm{C}$ por 7 dias em BDA, foram coletados em $10 \mathrm{~mL}$ de água, contendo $0,1 \%$ de Tween 80 . No preparo de inóculo, $10^{7}$ conídeos foram transferidos para erlenmeyer de $250 \mathrm{~mL}$, contendo $100 \mathrm{~mL}$ de meio milho e incubados a $25^{\circ} \mathrm{C}$ por 48 horas. A seguir, uma série de 7 erlenmeyers de $125 \mathrm{~mL}$, contendo $30 \mathrm{~mL}$ de meio milho, em duplicata, foi inoculada com $1,5 \mathrm{~mL}$ de cultura e incubada a $25{ }^{\circ} \mathrm{C}$ em cultivo estático. A fermentação foi interrompida no $5^{\circ}, 10^{\circ}, 15^{\circ}$, $20^{\circ}, 30^{\circ}, 40^{\circ}$ e $50^{\circ}$ dia, centrifugando-se o cultivo a $5.000 \times$ g a $4^{\circ} \mathrm{C}$ por 10 $\mathrm{min}$. Determinaram-se no sobrenadante (extrato bruto) obtido, a atividade amilásica, proteína solúvel e atividade específica, estando esta última relacionada com o tempo de produção das amilases para construir as respectivas curvas. 


\subsection{PRODUÇÃO DE AMILASE}

A amilase de $A$. flavus e $F$. moniliforme foi produzida pela transferência de $24 \mathrm{~mL}$ do inóculo para erlenmeyer de $2.000 \mathrm{~mL}$, contendo $480 \mathrm{~mL}$ de meio milho. $\mathrm{O}$ cultivo foi incubado a $25^{\circ} \mathrm{C}$, em cultivo estático durante 15 dias, empregando-se as condições padronizadas no item 2.3. A fermentação foi interrompida e o cultivo centrifugado a $5.000 \times \mathrm{g} \mathrm{a} 4{ }^{\circ} \mathrm{C}$ durante $10 \mathrm{~min}$. No extrato bruto foram determinadas a atividade amilásica, proteína solúvel e atividade específica.

\subsection{PRECIPITAÇÃO FRACIONADA DAS AMILASES}

$\mathrm{O}$ extrato bruto foi submetido a precipitação com $\left(\mathrm{NH}_{4}\right)_{2} \mathrm{SO}_{4}$ entre 0 e $20 \%$ de saturação, a $4{ }^{\circ} \mathrm{C}$, centrifugada a $30.000 \times \mathrm{g}$ a $4{ }^{\circ} \mathrm{C}$ durante $15 \mathrm{~min}$. No sobrenadante $S_{20}$ procedeu-se precipitação fracionada até $30 \%$ de saturação, seguida de $40 \%$ e sucessivamente até $100 \%$ de saturação com $\left(\mathrm{NH}_{4}\right)_{2} \mathrm{SO}_{4}$. Os precipitados $\left(\mathrm{P}_{20}, \mathrm{P}_{30}, \ldots \mathrm{P}_{100}\right)$ foram solubilizados em tampão $\mathrm{KH}_{2} \mathrm{PO}_{4}-\mathrm{NaOH} 0,05 \mathrm{M}, \mathrm{pH} 6,0$ e dialisados contra o mesmo tampão. No extrato dialisado foram determinados o teor de proteína solúvel, atividade amilásica e respectiva atividade específica, visando obter o perfil da atividade específica em função da porcentagem de saturação.

O intervalo entre $60-90 \%$ de saturação com $\left(\mathrm{NH}_{4}\right)_{2} \mathrm{SO}_{4}$, na recuperação da amilase fúngica foi estabelecido com base nos dados obtidos. O precipitado $\left(\mathrm{P}_{60-90}\right)$ foi solubilizado e dialisado contra água destilada e utilizado na determinação do $\mathrm{pH}$ e temperatura ótimos de atividade e estabilidade da amilase de $A$. flavus e $F$. moniliforme.

\subsection{CARACTERIZAÇÃO PARCIAL DAS AMILASES FÚNGICAS}

Para determinação de $\mathrm{pH}$ e temperatura ótimos utilizou-se delineamento experimental, denominado de planejamento em estrela, conforme descrito por BARROS NETO et al. (1995). As variáveis consistiram de $\mathrm{X}_{1}=$ temperatura de reação avaliada no intervalo de $-2,4$ a $82,4{ }^{\circ} \mathrm{C}$ e $\mathrm{X}_{2}=\mathrm{pH}$ no intervalo de 3,0 a 9,0, em 5 níveis, totalizando 11 experimentos com 3 repetições no ponto central. Nos ensaios aleatorizados foram avaliados $\mathrm{pH}$ e temperatura ótimos, medindo-se a atividade amilásica. As funções respostas, expressas em atividade específica de amilase de $F$. moniliforme e A. flavus, foram transformadas em logarítmo neperiano para assegurar a normalidade (BOX \& DRAPPER, 1987). As análises de regressão e variância foram realizadas no programa SAS (Statistical Analyses Sistems), versão 6.12 e os gráficos no programa STATISTICA versão 5.

Determinou-se a estabilidade térmica das amilases fúngicas, utilizando-se o mesmo delineamento citado anteriormente, porém alterando as variáveis 
para $\mathrm{X}_{3}=$ tempo entre 13,8 a 56,2 min e $\mathrm{X}_{4}=$ temperatura, variando de 0,4 a $79,6^{\circ} \mathrm{C}$. Neste delineamento manteve-se o $\mathrm{pH}$ fixo em 5,5 para $A$. flavus e 6,7 para $F$. moniliforme, procedendo-se também os ensaios aleatorizados. A atividade amilásica residual foi determinada a $40{ }^{\circ} \mathrm{C}$, conforme estabelecido anteriormente. As funções respostas foram expressas em atividade específica para amilase de $F$. moniliforme e $A$. flavus, respectivamente e transformadas em logarítmo neperiano para assegurar a normalidade (BOX \& DRAPPER, 1987).

\subsection{DETERMINAÇÃO DE ATIVIDADE ENZIMÁTICA}

A atividade amilásica foi determinada pelo método iodométrico (WILSON \& INGLEDEW 1982), em que 1 unidade de atividade amilásica (1U) corresponde a degradação de $0,1 \mathrm{mg}$ de amido em 10 min de reação, na presença de $5 \mathrm{mg}$ de substrato.

Determinou-se o teor de proteína pelo método de LOWRY et al. (1951).

A atividade específica foi expressa pela relação entre atividade amilásica e concentração de proteína (U/mg).

\section{RESULTADOS E DISCUSSÃO}

\subsection{PADRONIZAÇÃO DE FERMENTAÇÃO PARA AMILASES FÚNGICAS}

As Figuras 1 e 2 mostram, respectivamente, os resultados da produção de amilase por $F$. moniliforme e $A$. flavus, em relação ao tempo de cultivo. Observou-se atividades específicas máximas de $90,00 \mathrm{U} / \mathrm{mg}$ de proteína para $F$. moniliforme e $1.373,21 \mathrm{U} / \mathrm{mg}$ para $A$. flavus, sendo tais valores atingidos no $15^{\circ}$ dia de fermentação. Este tempo foi superior aos encontrados na literatura, já que a produção máxima de amilase em Penicillium expansum, visando obter maltose de amido ocorreu após 3 dias de fermentação (DOYLE et al., 1989), enquanto que Fusidium spp exigiu 2 dias e 20 horas (OHNO et al., 1992). SAHA \& BOTHAST (1993) obtiveram atividade máxima de amilase em Aureobasidium pullulans após 4 dias de fermentação. SHAH et al. (1991) demonstraram que o tempo de incubação também dependeu de características do meio, já que Aspergillus oryzae produziu melhor após 6 dias de fermentação em meio líquido, em relação a 2,5 dias em meio sólido.

A produção máxima de amilase em $F$. moniliforme (Figura 1) e $A$. flavus (Figura 2) no $15^{\circ}$ dia de fermentação se deve, provavelmente, ao prolongamento da fase logarítmica de crescimento no meio milho, que consiste de substrato altamente nutritivo. Supõe-se que a atividade 
amilásica máxima ocorra no final desta fase, tendo em vista que inicialmente os fungos utilizariam glucose, frutose, sacarose $e$ os aminoácidos livres existentes no milho verde. A produção de amilase seria estimulada pelo amido proveniente do milho maduro, após esgotar reservas de mono e dissacarídios. Assim, observou-se que houve retardamento no pico de produção de amilase, porém o incremento inicial de biomassa assegurou maior quantidade de amilase produzida.

\section{FIGURA 1 - PRODUÇÃO DE AMILASE POR F. moniliforme 113F}

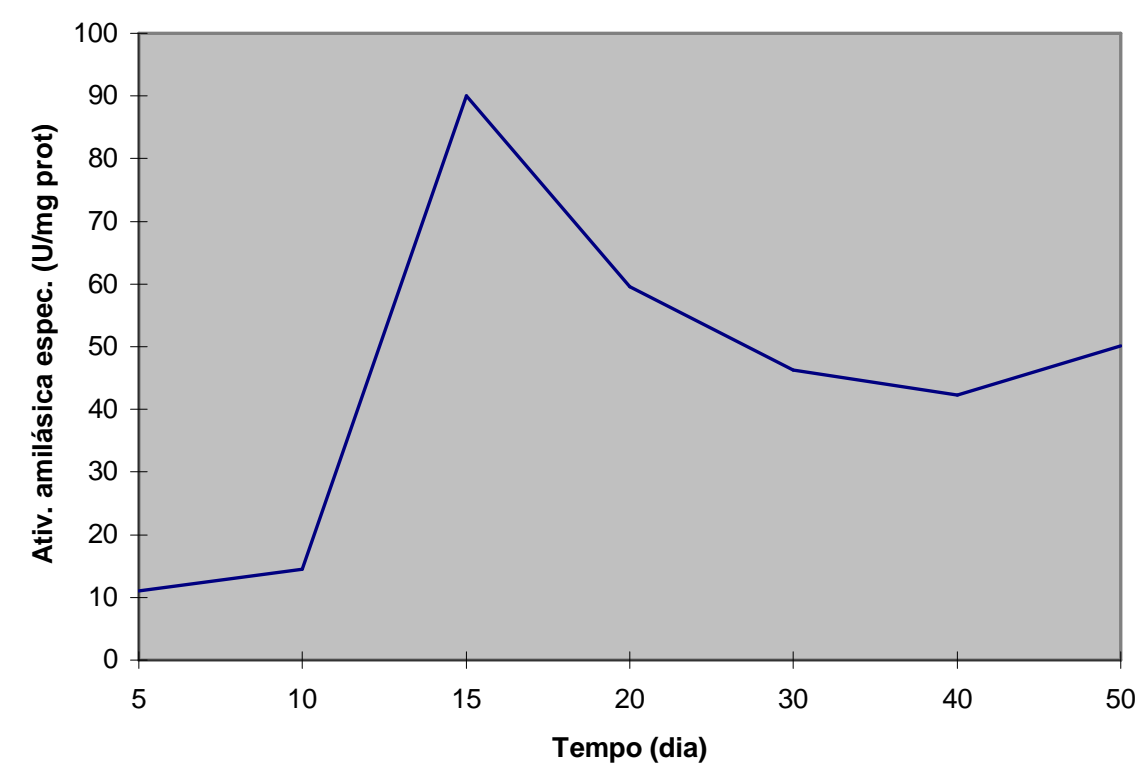

Salienta-se que a atividade máxima de amilase de $A$. flavus foi dez vezes maior que a de $F$. moniliforme. $O$ fato explicaria em parte, a predominância de $F$. moniliforme endofítico em nível de campo, no estágio de milho leitoso. Em contrapartida, as características inerentes de $A$. flavus favoreceria a sobrevivência em pós-colheita, que se manifesta na armazenagem, estando tal constatação de acordo com WATSON \& RAMSTAD (1987).

\subsection{PRECIPITAÇÃO FRACIONADA DE AMILASES FÚNGICAS}

A precipitação fracionada da amilase de $A$. flavus com $\left(\mathrm{NH}_{4}\right)_{2} \mathrm{SO}_{4}$ recuperou a atividade enzimática, no intervalo de 60 a 90\% de saturação (Figura 3). A amilase de F. moniliforme também apresentou perfil similar, sendo que pequena fração com baixa atividade específica precipitou na região de 30 a $50 \%$ de saturação (Figura 4). Estes resultados diferem de SAHA \& BOTHAST (1993) e OHNO et al. (1992), que fracionaram a alfa- 
amilase de Aureobasidium pullulans e Fusidium spp no intervalo de 0 a $80 \%$ de saturação.

\section{FIGURA 2 - PRODUÇÃO DE AMILASE POR A. flavus}

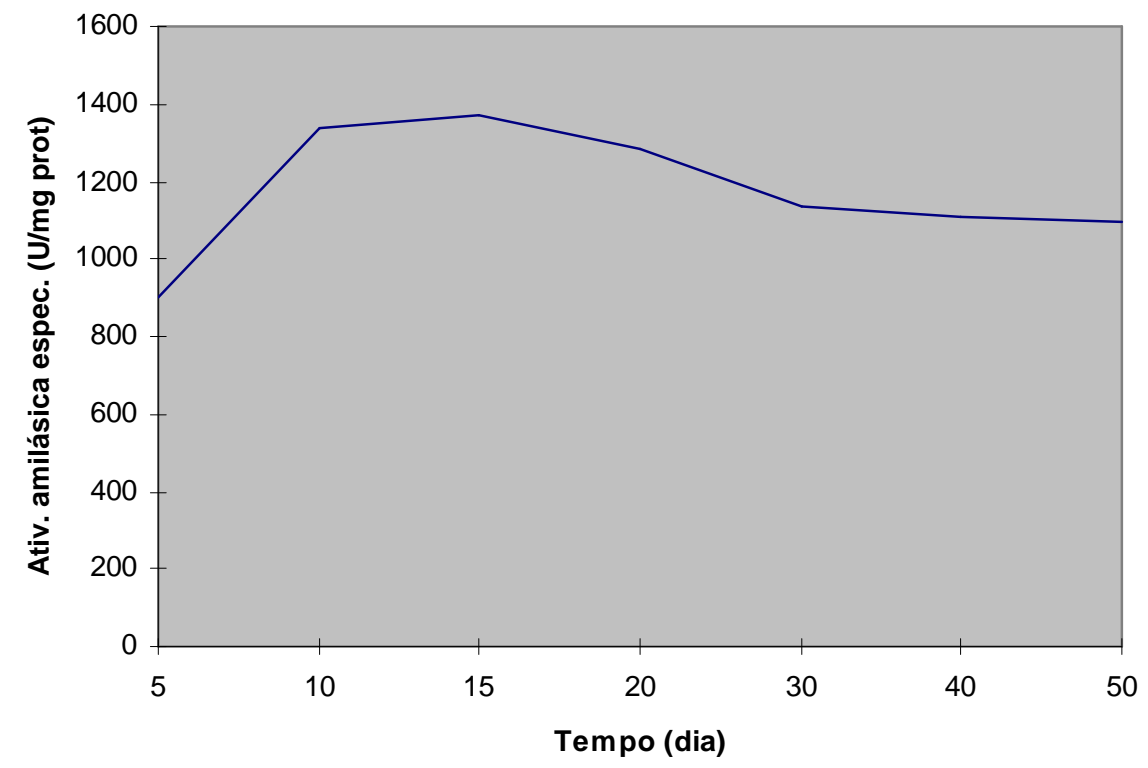

O fracionamento com $\left(\mathrm{NH}_{4}\right)_{2} \mathrm{SO}_{4}$ entre $60-90 \%$ de saturação indicou o caráter hidrofílico das amilases fúngicas estudadas (Figura 1 e 2), que necessitaram de alta concentração salina para remover água de hidratação e promover a precipitação.

FIGURA 3 - PRECIPITAÇÃO FRACIONADA DA AMILASE DE A. flavus

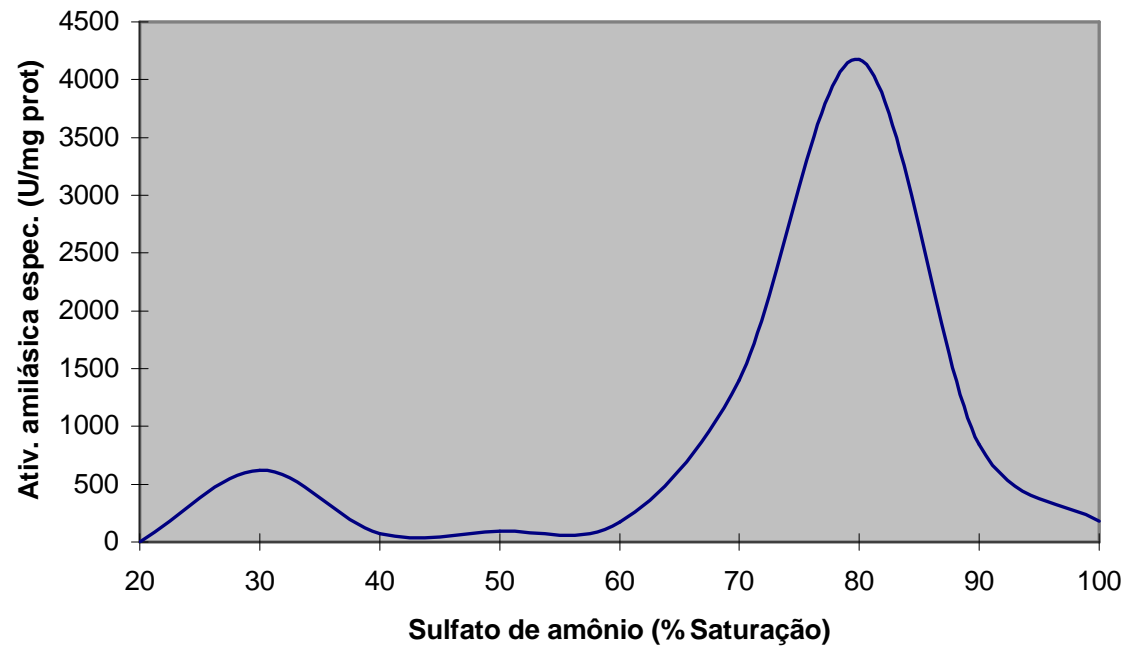




\section{FIGURA 4 - PRECIPITAÇÃO FRACIONADA DA AMILASE DE F. moniliforme 113F}

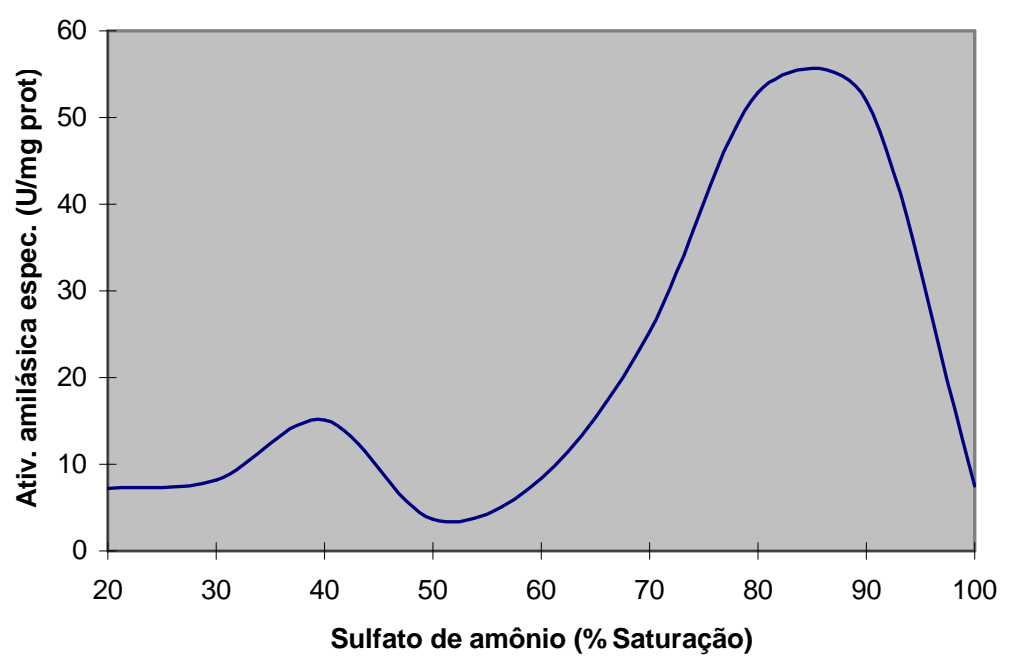

\subsection{CARACTERIZAÇÃO PARCIAL DAS AMILASES FÚNGICAS}

Obteve-se o modelo matemático apenas com parâmetros significativos, i.e, referentes a análise da temperatura e $\mathrm{pH}$ da amilase de $F$. moniliforme 113F (Figura 5) e A. flavus (Figura 6), assim como para a estabilidade da amilase de $F$. moniliforme 113F (Figura 7 ), porém não se determinou o mesmo para $A$. flavus.

A regressão linear, quadrática e completa foi significativa $(p<0,05)$ para os efeitos de $\mathrm{pH}$, temperatura e estabilidade térmica da amilase de $F$. moniliforme. No que se refere aos efeitos de $\mathrm{pH}$ e temperatura na amilase de $A$. flavus, apenas a regressão quadrática e completa foi significativa $(p<0,05)$. Entretanto, a falta de ajuste foi, também, significativa para ambas as análises de variância, devido ao baixo nível de erros puros nos quadrados médios, ou seja, da ordem de $10^{-3}$ a $10^{-6}$. Segundo BOX \& DRAPER (1987) o teste de significância para a falta de ajuste não deve ser considerado relevante, caso os quadrados médios do erro puro sejam muito baixos. Conseqüentemente, na análise de variância obteve-se coeficiente de determinação total $\left(R^{2}\right)$ de 0,$95 ; 0,92$ e 0,98 , indicando que o modelo explicou 95 e 92 das variações para temperatura e $\mathrm{pH}$ da amilase de $F$. moniliforme e $A$. flavus, além de $98 \%$ das variações para a estabilidade térmica da amilase de F. moniliforme, demonstrando ajuste adequado do modelo aos dados experimentais. O coeficiente de variação (c.v.) foi de 10,$94 ; 12,80$ e $6,30 \%$, respectivamente, para temperatura e $\mathrm{pH}$ 
da amilase de $F$. moniliforme e $A$. flavus e estabilidade térmica da amilase de $F$. moniliforme, indicando baixa variabilidade nos resultados.

\section{FIGURA 5 - SUPERFÍCIE DE RESPOSTA DOS EFEITOS DE TEMPERATURA E PH SOBRE ATIVIDADE AMILÁSICA DE F. moniliforme}

$$
\begin{gathered}
\mathrm{LN} \mathrm{Y}_{\mathrm{T} . \mathrm{pH} 1}=4,0003+0,4291 \mathrm{x}_{2}-0,9880 \mathrm{x}_{1}{ }^{2}-0,6609 \mathrm{x}_{2}{ }^{2} \\
( \pm 0,18)( \pm 0,11)( \pm 0,13) \quad( \pm 0,13)
\end{gathered}
$$

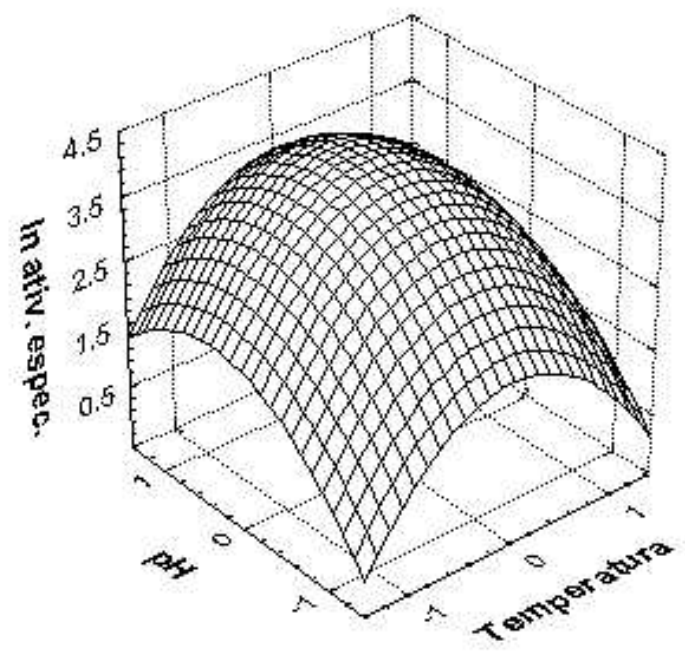

FIGURA 6 - SUPERFÍCIE DE RESPOSTA DOS EFEITOS DE TEMPERATURA E PH SOBRE ATIVIDADE AMILÁSICA DE A. flavus

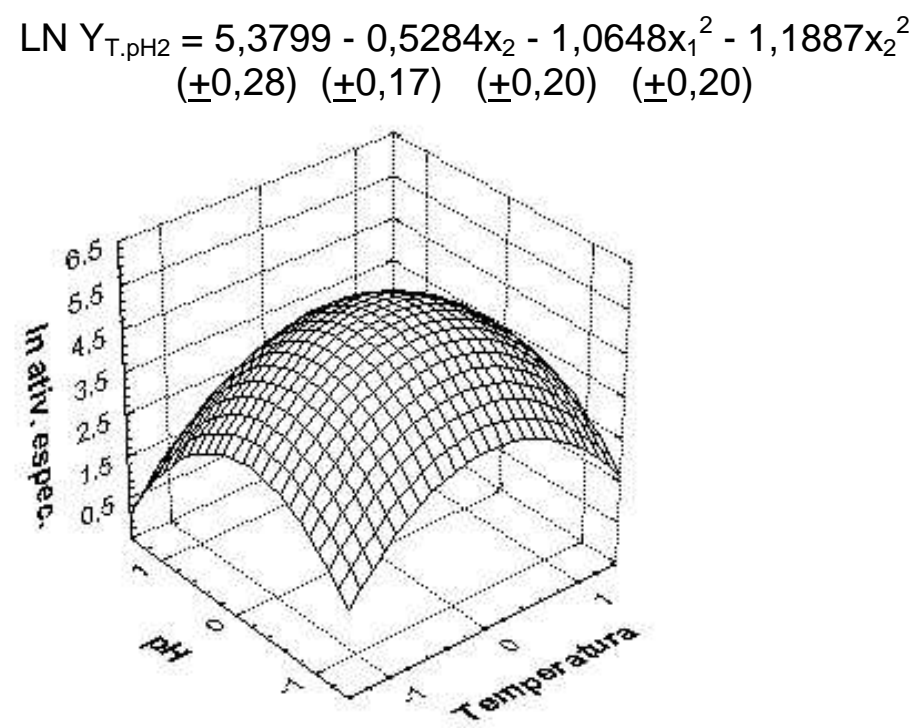




\section{FIGURA 7 - SUPERFÍCIE DE RESPOSTA DOS EFEITOS DA ESTABILIDADE TÉRMICA SOBRE ATIVIDADE AMILÁSICA DE F. moniliforme}

$$
\begin{gathered}
\mathrm{LN} \mathrm{Y}_{\mathrm{t} . \mathrm{T} 3}=4,0868-0,9603 \mathrm{x}_{2}-0,7830 \mathrm{x}_{2}^{2} \\
( \pm 0,12)( \pm 0,07) \quad( \pm 0,09)
\end{gathered}
$$

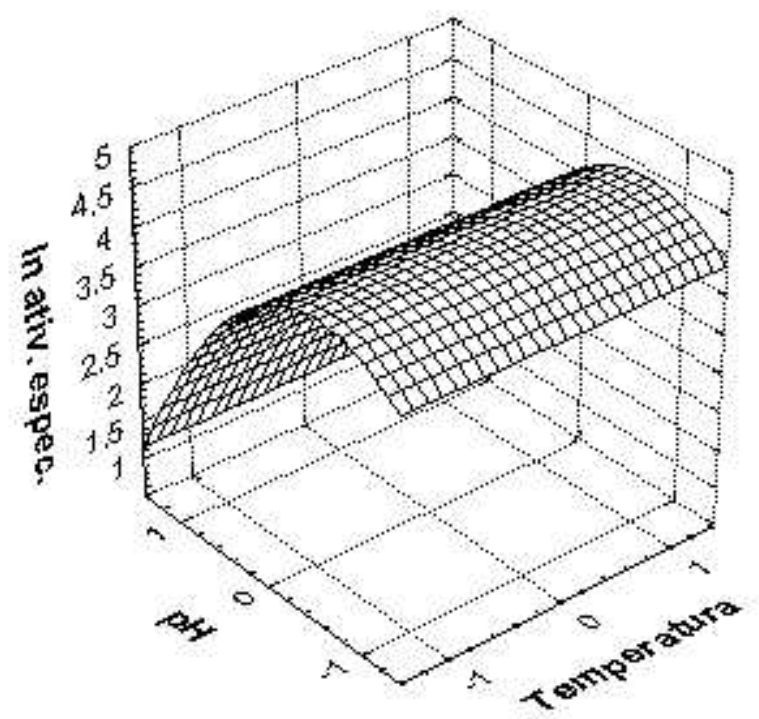

Verificou-se que a atividade amilásica (Figuras 5 e 6) tende ao máximo na proximidade de $40{ }^{\circ} \mathrm{C}$, em ambos os fungos e $\mathrm{pH} 5,5$ e 6,7 , respectivamente para $A$. flavus e $F$. moniliforme. De acordo com a Figura 7 a máxima estabilidade térmica da amilase de $F$. moniliforme ocorreu na região próxima a $21,0{ }^{\circ} \mathrm{C}$. Estes resultados indicam que a atividade $\mathrm{e}$ estabilidade (Figuras 5 e 7) tenderam a maximização, nas condições de maior crescimento fúngico $\left(22,5\right.$ a $27,5^{\circ} \mathrm{C}$ e pH próximo de 7,0$)$, conforme já descrito por BACON \& NELSON (1994) e MARíN et al. (1995).

Em termos práticos, a produção de amilase nos fungos micotoxigênicos tem como utilidade fornecer substrato adequado para o estudo de inibidores enzimáticos, visando controle mediante mecanismos naturais de defesa de planta. Assim sendo, os resultados apresentados demonstraram constância na atividade amilásica em dada temperatura (Figura 7). $\mathrm{O}$ fato viabiliza o ensaio com os inibidores, cuja reação inicia-se com préincubação da enzima e do inibidor (IDA et al., 1994) no intervalo de tempo e temperatura utilizado na avaliação da estabilidade térmica (Figura 7). A mesma figura indica que a redução na atividade seria exclusivamente decorrente de ação dos inibidores enzimáticos, já que o fator tempo não 
influenciou na atividade amilásica, na faixa em que ocorreu maior sensibilidade da reação. Os resultados referentes a temperatura e $\mathrm{pH}$ da amilase de fungos micotoxigênicos podem fornecer os parâmetros necessários ao estudo posterior sobre inibidores, tendo em vista que a caracterização do substrato complementaria a interação enzimática.

\title{
4 CONCLUSÃO
}

A maximização da produção de amilase em $F$. moniliforme e $A$. flavus no meio milho ocorreu no $1^{\circ}$ dia de fermentação, cuja enzima apresentou característica hidrofílica, precipitando-se no intervalo entre 60 a $90 \%$ de saturação salina. A metodologia de superfície de resposta explicou de 92 a $98 \%$ das variações ocorridas para temperatura, $\mathrm{pH}$ e estabilidade térmica de amilases. A enzima de $F$. moniliforme mostrou-se estável em temperatura ambiente, cuja maximização de atividade ocorreu próximo a $40^{\circ} \mathrm{C}$ em $\mathrm{pH} 5,5$ e 6,7, respectivamente, para $F$. moniliforme e $A$. flavus.

\begin{abstract}
Regarding the economic relevance of corn culture and the fact that it can be a target to micotoxigenic fungi under improper storage conditions, this research aims the production of amylase and its partial biochemical characterization of the main problematic species Fusarium moniliforme and Aspergillus flavus. The fungi were cultivated in prepared medium containing both unripe and ground corn kernels. Maximum amylase production occurred on the $15^{\text {th }}$ day of fermentation for both strains. The supernatant phase was fractionally precipitated with ammonium sulfate between 60 and $90 \%$ of saturation and the separated amylase had its parameters $(\mathrm{pH}$, temperature and thermal stability) characterized by response surface methodology. Maximum activity was obtained at $40^{\circ} \mathrm{C}$ and $\mathrm{pH}$ of 6.7 for the amylase of $F$. moniliforme and $\mathrm{pH}$ of 5.5 for the amylase of $A$. flavus. The optimal thermal stability for the enzyme of $F$. moniliforme occurred at $21^{\circ} \mathrm{C}$.
\end{abstract}

\section{REFERÊNCIAS BIBLIOGRÁFICAS}

1 BACON, C. W., NELSON, P. E. Fumonisin production in corn by toxigenic strains of Fusarium moiliforme and Fusarium proliferatum. Journal of Food Protection, v. 57, n. 6, p. 514-521, 1994.

2 BARROS NETO, B., SCARMINIO, I. S., BRUNS, R. E. Planejamento e otimização de experimentos. Campinas : Editora da UNICAMP, 1995. 299 p.

3 BEZUIDENHOUT, S. C., GELDERBLOM, W. C. A., GORSTALLMAN, C. P., HORAK, R. M., MARASAS, W. F. O., SPITELLER, G., VLEGGAAR. R. Structure elucidation of the fumonisins, mycotoxins from Fusarium moniliforme. Chemical

Communications, London, p. 743-745, 1988. 
$4 \quad$ BOX, G. E. P., DRAPER, N. R. Empirical model-building and response surfaces. 3.ed. New York : John Wiley, 1987. $669 \mathrm{p}$.

5 BULLERMAN, L. B., DRAUGHON, F. A. Fusarium moniliforme and fumonisin symposium - introduction. Journal of Food Protection, Ames, v. 57, n. 6, p. 523, 1994.

6 CÔRTEZ, C. Pesquisa prioriza o consumo humano. Folha de Londrina, Londrina, 16 ago. 1997. Folha Rural, p. 9.

7 DOKO, M. B., RAPIOR, S., VISCONTI, A., SCHJOTH, J. E. Incidence and levels of fumonisin contamination in maize genotypes grown in Europe and Africa. J. Agric. Food Chem., v. 43, p. 429-434, 1995.

8 DOYLE, E. M., KELLY, C. T., FOGARTY, W. M. The high maltoseproducing $\alpha$-amylase of Penicillium expansum. Appl. Microbiol. Biotechnol, v. 30, p. 492-496, 1989.

9 FIGUEIRA, E. L. Z. Otimização de cultivo e produção de amilase fúngica visando o controle de Fusarium moniliforme em milho (Zea mays) por inibidores de amilase. Londrina, 1999. 109 p. Dissertação (Mestrado) - Departamento de Tecnologia de Alimentos e Medicamentos, UEL.

10 GATEhOUSE, A. M. R., HILDER, V. A., GATEHOUSE, J. A. Control of insect pests by plant genetic engineering. Proceedings of the Royal Soceity of Edinburgh, Edinburgh, v. 99B, n. 3/4, p. 51-60, 1992.

11 GOMES, V. M., XAVIER-FILHO, J. Biochemical defenses of plants. Arq. Biol. Tecnol., Curitiba, v. 37, n. 2, p. 371-383, 1994.

12 GONZÁLEZ, H. H. L., RESNIK, S. L., BOCA, R. T., MARASAS, W. F. $O$. Mycoflora of Argentinian corn harvested in the main production area in 1990. Mycopathologia, Dordrecht, v. 130, p. 29-36, 1995.

13 IDA, E. I., FINARDI-FILHO, F., LAJOLO, F. M. Purification and partial characterization of two proteinaceous $\alpha$-amylase inhibitors from titicale. Journal of Food Biochemistry, Westport, v. 18, p. 83102, 1994.

14 HIROOKA, E. Y., YAMAGUCHI, M. M., AOYAMA, S., SUGIURA, Y., UENO, Y. The natural occurrence of fumonisins in Brazilian corn kernels. Food Additives and Contaminants, London, v. 13, n. 2, p. 178-183, 1996. 
15 JULIAN, A. M., WAREING, P. W., PHILIPS, S. I., MEDLOCK, V. F. P., MACDONALD, M. V., RÍO, L. E. Fungal contamination and selected mycotoxins in pre- and post-harvest maize in Honduras. Mycopathologia, Dordrecht, v. 129, p. 5-16, 1995.

16 LOWRY, O. H., ROSEBROUGH, N. J., FARR, A. L., RANDALL, R. J. Protein measurement with the foin phenol reagent. J. Biol. Chem, Baltimore, v. 193, p. 265-275, 1951.

17 LOGRIECO, A., MORETTI, A., RITIENI, A., BOtTALICO, A., CORDA, $P$. Occurrence and toxigenicity of Fusarium proliferatum from preharvest maize ear rot, and associated mycotoxin, in Italy. Plant Disease, St. Paul, v. 79, n. 7, p. 727-731, 1995.

18 MARÍN, S., SANCHIS, V., MAGAN, N. Water activity, temperature, and $\mathrm{pH}$ effects on growth of Fusarium moniliforme and Fusarium prliferatum isolates from maize. Canadian Journal Microbiology, v. 41, p. 1063-1070, 1995.

19 NORRED, W. P., VOSS, K. A. Toxicity and role of fumonisins in animal diseases and human esophageal cancer. Journal of Food Protection, Ames, v. 57, n. 6, p. 522-527, 1994.

20 OHNO, N., IJUIN, T., SONG, S., UCHIYAMA, S., SHINOYAMA, H., ANDO, A., FUJII, T. Purification and properties of amylases extracellulary produced by an imperfect fungus, Fusidium sp BX-1 in a glycerol medium. Bioscience, Biotechnology, and Biochemistry, Tokyo, v. 56, n. 3. p. 465-471, 1992.

21 ROSS, P. F., RICE, L. G., PLATTNER, R. D., OSWEILER, G. D., WILSON, T. M., OWENS, D. L., NELSON, H. A., RICHARD, J. L. Concentrations of fumonisin $\mathrm{B}_{1}$ in feeds associated with animal health problems. Mycopathologia, Dordrecht, v. 114, p. 129135, 1991.

22 SAHA, B., BOTHAST, R. J. Starch conversion by amylases from Aureobasidium pullulans. Journal of Industrial Microbiology, v. 12, p. 413-416, 1993.

23 SHAH, N. K., RAMAMURTHY, V., KOTHARI, R. M. Comparative profiles of fungal alpha amylase production by submerged and surface fermentation. Biotechnology Letters, v. 13, n. 5, p. 361364, 1991.

24 THIEL, P. G. et al. Survey of fumonisin production by Fusarium species. Applied and Environmental Microbiology, Washington, v. 57, n. 4, p. 1089-1093, 1991. 
25 WATSON, S. A., RAMSTAD, P. E. (Ed.). Corn: chemistry and technology. St. Paul : American Association of Cereal Chemist, 1987. $605 \mathrm{p}$.

26 WEIBKING, T. S., LEDOUX, D. R., BERMUDEZ, A. J., TURK, J. R., ROTTINGHAUS, G. E., WANG, E., MERRILL, JR. A. H. Effects of feeding Fusarium moniliforme culture material, containing know levels of fumonisin $\mathrm{B}_{1}$, on the young broiler chick. Poutry Science, Savoy, v. 72, n. 3, p. 456-465, 1993.

27 WILSON, J. J., INGLEDEW, W. M. Isolation and characterization of Schwanniomyces alluvius amylolytic enzymes. Applied and Environmental Microbiology, Washington, v. 44, n. 2, p. 301-307, 1982.

\section{AGRADECIMENTOS}

Os autores agradecem ao CNPq pelo apoio financeiro, CAPES pela bolsa de mestrado concedida ao primeiro autor e aos professores Fábio Yamashita e Rui Sérgio dos Santos Ferreira da Silva pelas análises estatísticas. 